\title{
PANORAMA DOS CURSOS DE GRADUAÇÃO EM BIBLIOTECONOMIA A DISTÂNCIA OFERECIDOS NO RIO GRANDE DO SUL (RS)
}

\section{OVERVIEW OF LIBRARIANSHIP GRADUATION COURSES BY DISTANCE OFFERED IN RIO GRANDE DO SUL (RS)}

Andressa Tornquist Curso de Graduação em Biblioteconomia, Universidade Salgado de Oliveira Brasil

Submetido em: 29/06/2020

Aceito em: 03/12/2020

Publicado em: 24/12/2020

Licença:

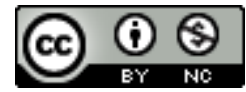

Autor para correspondência: Andressa Tornquist

Email: andressatornquist@outlook.com

ORCID: 0000-0003-3410-8741

\section{Como citar este artigo:}

TORNQUIST, Andressa. Panorama dos Cursos de Graduação em Biblioteconomia a distância oferecidos no Rio Grande do Sul (RS). REBECIN, São Paulo, v. 7, n. 2, p. 2345, jul./dez. 2020. DOI: 10.24208/rebecin.v7i2.191 


\section{RESUMO}

Este artigo trata do ensino de Biblioteconomia a distância no Rio Grande do Sul e objetiva traçar um panorama do oferecimento desses cursos. A pesquisa inicia-se com busca de referencial teórico; desenvolve-se a partir da pesquisa no site do Sistema E-MEC do Ministério da Educação e da coleta de dados nos sites das instituições que oferecem tal curso a distância, buscando caracterizar tais cursos. Cinco são as universidades que os oferecem: quatro privadas e uma pública. O valor médio cobrado pelas mensalidades é de $R \$ 258,30$. Os cursos têm duração média de 2.557,5 horas. Algumas universidades focam seus currículos nas disciplinas de conhecimentos gerais; outras em disciplinas relacionadas à informação e às TICs. Algumas disciplinas são comuns em todos os cursos analisados. Todos os cursos alvo desta pesquisa possuem autorização para funcionamento; no entanto, ainda nem todos foram avaliados pelo MEC. A Biblioteconomia é vista como uma profissão promissora por todas as universidades. Percebe-se que os cursos atendem ao exigido legalmente e também às demandas da formação profissional para o mercado de trabalho do Rio Grande do Sul.

Palavras-Chave: Ensino de Biblioteconomia; Ensino a distância; Faculdades de Biblioteconomia.

\section{ABSTRACT}

This article deals with the library education by distance at Rio Grande do Sul and objetives to draw an overview of the offering of these courses. The research starts with the search for theoretical reference; it develops from the research on the website of the E-MEC System of the Education Ministry and from the collection of data on the websites of the institutions that offer that courses, seeking to characterize them. Five are the universities that offer that courses: four private, one public. The average amount charged for the monthly payment is $\mathrm{R} \$ 258,30$. Distance learning courses have an average duration of $2.557,5$ hours. Some universities focus their curricula on general knowledge subjects; others focus their curricula on information and ICT related subjects. Some subjects are common in all analyzed courses. All courses targeted by this research are authorized to operate; however, not all have yet been evaluated by MEC. Librarianship is seen as a promising profession by all universities. It is noticed that the courses meet the legal requirements and also the demands of professional training for the labor market of Rio Grande do Sul.

Keywords: Library education; Distance learning; Library schools.

\section{INTRODUÇÃO}

Bibliotecas são instituições antigas na humanidade. Bibliotecários também. Nossa profissão tem mudado nas últimas décadas face, principalmente, aos avanços da tecnologia da informação, assim como, também tem acontecido com a Educação. Novos paradigmas, novas modalidades de ensino. Ampliação da oferta de cursos a distância e explosão do número de matriculados nesta modalidade. Neste artigo, focase nos cursos de Biblioteconomia oferecidos no Rio Grande do Sul na modalidade a distância. Problematiza-se a caracterização dos mesmos, objetivando-se a delimitação de um panorama sobre seu oferecimento. 


\section{PROFISSIONAL BIBLIOTECÁRIO}

Para Machado (2012), o Bibliotecário na Antiguidade tinha o status de sábio, de estudioso, de intelectual. Na Idade Média, tinha o status de devoto, estranho guardião do saber. Já no final do século XX, tem o status de disseminador da informação.

No Brasil, o mercado de trabalho do Bibliotecário, passou a ser identificado enquanto tal, a partir da criação do primeiro curso da área em 1911, conforme Nascimento e Martins (2017). A profissão, de acordo com Machado (2012), foi oficialmente reconhecida no Brasil em 1962, através da Lei 4.084, de 30 de junho (atualizada em 1998, através da lei 9.674, sem grandes alterações). Nela, listam-se as atribuições do Bibliotecário: organização, direção e execução de serviços técnicos referentes ao ensino de Biblioteconomia; fiscalização de estabelecimentos de ensino de Biblioteconomia; administração e direção de bibliotecas; organização e direção de serviços de documentação, classificação e catalogação de manuscritos de livros raros, mapotecas, publicações oficiais e seriadas, de bibliografia e referência. A lei também lista os locais de trabalho do Bibliotecário: repartições públicas federais, estaduais, municipais, autarquias e empresas particulares.

A maioria dos autores concordam com Job e Oliveira (2006), quando estes dizem que o mercado de trabalho do Bibliotecário sofreu mudanças com o advento das tecnologias da informação. A sociedade da informação contribuiu não só para a formação de um novo perfil de profissional Bibliotecário, mas, também, para a valorização deste profissional: isso porque, segundo, Amaral (2015), a sociedade está focada no conhecimento, na valorização da informação, ambos foco do trabalho do Bibliotecário.

\section{FORMAÇÃO EM BIBLIOTECONOMIA}

A formação de Bibliotecários, conforme legislação vigente, deve acontecer em curso de nível superior. Os estudos de Paiva et al. (2017) apontam que, no Brasil, existem 41 cursos de Biblioteconomia distribuídos em todos os estados do país, oferecidos tanto por instituições públicas quanto privadas, tanto presenciais quanto a 
distância. Já Nascimento e Martins (2017), referem 50 destes cursos. Consulta ao Sistema E-MEC em novembro de 2020 informa 63 cursos de graduação em Biblioteconomia no Brasil. Neste número incluem-se cursos presenciais e a distância, de todos os tipos de universidades. Daí a importância de conhecê-los.

De acordo com Russo, Fonseca e Barbalho (2012), os primeiros cursos de Biblioteconomia surgem no século XIX na Europa e nos Estados Unidos. A École Nationale des Chartres, na França, em 1821, teria sido a pioneira mundial.

No Brasil, de acordo com Job e Oliveira (2006), a formação acadêmica em Biblioteconomia tem início em 1911, quando da criação do curso de graduação na Biblioteca Nacional. Os autores afirmam que a profissão foi reconhecida formalmente em 1962, a partir da lei 4.084. Segundo Almeida e Baptista (2013), nesta época, também ocorre a padronização das disciplinas ofertadas em cursos de graduação em Biblioteconomia. O currículo mínimo de 1962 dividia-se em dois grandes grupos: conteúdo cultural e humanístico e, conteúdo de assuntos técnicos. Já em 1963, o Conselho Federal de Educação impunha mudanças nesses currículos, o que gerou descontentamento na área.

Almeida e Batista (2013) escrevem que, em 1982, um novo currículo foi proposto pelo Conselho Federal de Educação em parceria com a Associação Brasileira de Escolas de Biblioteconomia e Documentação (ABEBD). Este novo currículo dividia-se em três eixos: matérias de fundamentação geral, matérias instrumentais e matérias de formação profissional.

Na década de 1990, promulga-se a Lei de Diretrizes e Bases da Educação Nacional (LDB, Lei 9.394/1996). Deu-se às universidades autonomia para criar, organizar e extinguir cursos de ensino superior, além de fixar os currículos de cursos, obedecendo às diretrizes pertinentes.

As Diretrizes Curriculares Nacionais para o Curso de Biblioteconomia foram estabelecidas a partir dos Pareceres CNE/CES 492/2001 e CNE/CES 1.363/2001, bem como pela Resolução CNE/CES 19/2002. As diretrizes definiram o perfil dos formandos na área, enumeraram suas competências e habilidades para o exercício profissional, estabeleceram a importância dos estágios, atividades complementares e avaliações institucionais. As diretrizes são as bases para a organização do curso, que tem seus conteúdos divididos em gerais e específicos. Russo, Fonseca e Barbalho 
(2012) afirmam que, mesmo após todas as mudanças na legislação educacional e na sociedade como um todo, os cursos de graduação continuam oferecendo uma formação generalista.

\section{EDUCAÇÃO A DISTÂNCIA}

A LDB conceitua a Educação a Distância como uma modalidade educacional na qual a mediação didático-pedagógica nos processos de ensino e aprendizagem ocorre com a utilização de meios e tecnologias de informação e comunicação, com estudantes e professores desenvolvendo atividades educativas em lugares e tempos diversos.

Muitos pensam na educação a distância como algo recente, no entanto, não o é, como bem colocam Alves (2009), Litto (2009) e Nunes (2009). O ensino a distância já acontecia nos anos 1900 no Brasil. Também é importante lembrar que a Educação a Distância já faz parte da legislação educacional brasileira desde 1961. E que, no entanto, somente em 1996, esta modalidade recebeu um capítulo especial, abrindo-a para todos os níveis de ensino.

De acordo com Gomes (2009) e Abreu (2017), é a partir da promulgação da LDB que várias outras normas foram publicadas com o intuito de regulamentar a Educação a Distância. Entre estas normas temos: a Portaria Normativa ํㅡㄹ, de 10 de janeiro de 2007; o Decreto 5.622, de 19 de dezembro de 2005; o Decreto 5.773, de 9 de maio de 2006; o Decreto 6.303, de 12 de dezembro de 2007; a Resolução do Conselho Estadual de Educação do Estado do Rio Grande do Sul oㅡ 293, de 29 de agosto de 2007; a Resolução do Conselho Estadual de Educação do Estado do Rio Grande do Sul no 300, de 15 de julho de 2009; e, a Resolução no 1, de 11 de março de 2016.

Para Russo (2016), outro fato importante dentro da Educação a Distância no Brasil acontece em 2005: a criação da Universidade Aberta do Brasil (UAB), com o desafio de ampliar o ingresso ao nível superior para pessoas de todas as classes sociais.

Os censos da educação superior vêm apresentando resultados expressivos em relação a Educação a Distância. Há crescimento na oferta e na procura por este tipo 
de curso no Brasil. Segundo o Censo EAD.BR (2017), o total de matrículas, junto com o aumento de polos e a definição mais ampla de cursos semipresenciais, apresentou um crescimento muito significativo.

De acordo com Abreu (2017), a maioria das matrículas dos cursos a distância está na rede privada e a maior parte está em cursos de licenciatura. Os cursos de Educação a Distância, atualmente, representam, aproximadamente, 17,1\% das matrículas de graduação no país.

\section{BIBLIOTECONOMIA A DISTÂNCIA}

Segundo Russo (2016), as experiências relacionando Biblioteconomia e Educação a Distância, datam do final do século XIX, quando o bibliotecário americano Melvil Dewey convidou profissionais da Escola de Biblioteconomia de Albany para desenvolver cursos por correspondência. No Brasil, a autora escreve que as experiências nestas áreas têm ocorrido, mais significativamente, a partir dos últimos dez anos, focalizando o segmento do ensino de pós-graduação lato sensu.

Em se tratando de cursos de graduação em Biblioteconomia na modalidade a distância, Russo (2016) indica a Universidade de Caxias do Sul como pioneira; tendo sido seu curso lançado em 2012. Segundo a autora, a matriz curricular do curso totaliza 2.490 horas, distribuídas em 40 disciplinas, com dois requisitos correspondentes a Estágio em Biblioteconomia; ainda é acrescida de 120 horas complementares, totalizando 2.610 horas; não sendo registrado na matriz curricular o requisito de Trabalho de Conclusão de Curso.

Em 2014, a Universidade Salgado de Oliveira passa, também, a ofertar este curso nesta modalidade. Russo (2016) observa que há um fluxo programático que contempla 2.665 horas, contendo 46 disciplinas obrigatórias, duas optativas, dois requisitos curriculares de estágio supervisionado e dois de trabalho de conclusão de curso. Este fluxograma totaliza 177 créditos, a serem cumpridos em quatro anos. A autora reforça, ainda, que ambas universidades ofereciam o curso somente na modalidade a distância.

Já em 2016, de acordo com Russo (2016), iniciaram-se as atividades do Curso de Biblioteconomia a distância da Universidade Comunitária da Região de Chapecó. 
O curso está previsto para ser integralizado em sete períodos, com 179 créditos, correspondentes a 42 disciplinas, mais dois requisitos de Estágio Supervisionado e um de Trabalho de Conclusão de Curso. A matriz ainda determina que os estudantes participem de Atividades Curriculares, no mínimo de 105 horas.

Em 2008, a CAPES, a UAB e o Conselho Federal de Biblioteconomia (CFB), iniciaram o planejamento da oferta do curso de Biblioteconomia a Distância a nível nacional. As instituições de ensino que seriam responsáveis pela oferta deste curso seriam aquelas exclusivamente públicas, que já oferecessem cursos presenciais, visto que estas instituições poderiam suprir suas necessidades de infraestrutura. Há, assim, 14 instituições aptas a oferecer o Curso Nacional de Biblioteconomia na Modalidade a Distância (BibEaD). Em 2020, várias destas universidades já iniciaram suas seleções para referido curso; tendo sido a Universidade Federal de Sergipe (UFS) a primeira a iniciar as atividades acadêmicas (aulas).

Segundo informações do site da UAB, o Curso de Biblioteconomia na modalidade a distância tem a duração prevista de 4 (quatro) anos ou oito semestres. O total da carga horária do curso é de 2.895 horas, sendo 2.355 horas de disciplinas obrigatórias que incluem os Seminários Temáticos I e II, 240 horas de Estágio Supervisionado (obrigatório), 120 horas de atividades complementares e no mínimo 180 horas referentes a 6 (seis) disciplinas optativas. Os conteúdos curriculares foram organizados em oito eixos: Eixo 0: Módulo Básico; Eixo 1: Fundamentos Teóricos da Biblioteconomia e da Ciência da Informação; Eixo 2: Organização e Representação da Informação; Eixo 3: Recursos e Serviços de Informação; Eixo 4: Políticas e Gestão de Ambientes de Informação; Eixo 5: Tecnologias de Informação e Comunicação; Eixo 6: Pesquisa em Biblioteconomia e Ciência da Informação; Eixo 7: Estágios e Atividades Complementares.

\section{METODOLOGIA}

A pesquisa iniciou-se a partir de um estudo exploratório, baseando-se em uma revisão bibliográfica, que fez uso de fontes primárias e secundárias. O processo de revisão bibliográfica foi contínuo no decorrer da pesquisa. Após o estudo exploratório, 
iniciou-se um estudo descritivo, objetivando-se especificar as características dos cursos de biblioteconomia a distância oferecidos no Rio Grande do Sul (RS).

São sujeitos desta pesquisa todos os cursos de Biblioteconomia a distância oferecidos no Rio Grande do Sul (RS). As informações sobre quais são as instituições que oferecem tais cursos foram obtidas no site do Sistema E-MEC do Ministério da Educação. A consulta foi realizada no primeiro semestre de 2019.

Para a coleta de dados utilizou-se da observação não estruturada, com categorias gerais abertas e com liberdade de observação. $O$ tratamento dos dados obtidos através da observação é misto. Como colocam Sampieri, Collado e Lucio (2013), uma análise de dados mista implica a coleta e a análise de dados quantitativos e qualitativos, assim como sua integração e discussão conjunta, objetivando um entendimento maior do fenômeno.

\section{ANÁLISE DOS DADOS}

A pesquisa, realizada em 2019, iniciou-se com a delimitação de sua amostra. Para tal, foi feita uma consulta no sistema E-MEC, a fim de verificar quantos e quais são os cursos de Biblioteconomia a distância oferecidos no Rio Grande do Sul. Como resultado, vê-se a figura 1 abaixo:

Figura 1: resultado da consulta no Sistema E-MEC.

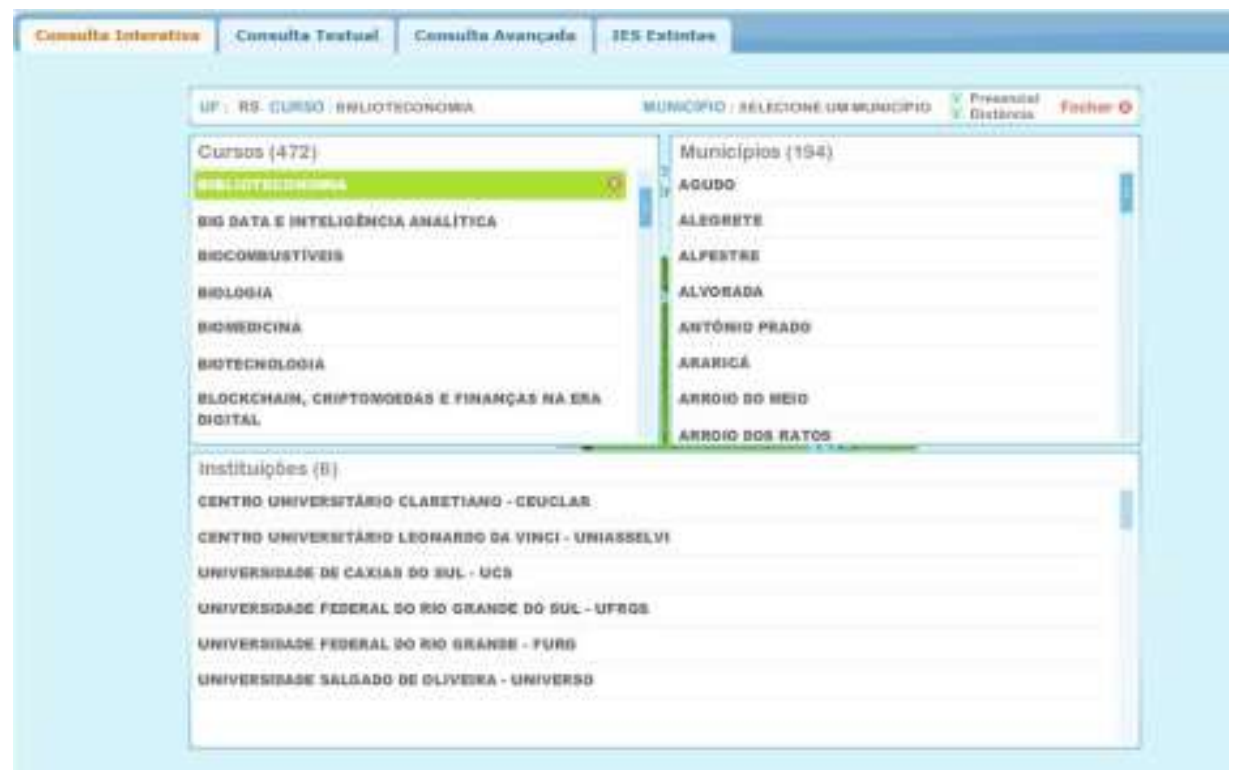

Fonte: http://emec.mec.gov.brl. Acesso em jul. 2019. 
Do resultado acima, excluiu-se, para fim desta pesquisa, a Universidade Federal do Rio Grande (FURG), pois oferece o curso de Biblioteconomia somente na modalidade presencial. Disto, resultaram como amostra os cursos oferecidos pelas seguintes instituições: Centro Universitário Claretiano - CEUCLAR; Centro Universitário Leonardo da Vinci - UNIASSELVI; Universidade de Caxias do Sul - UCS; Universidade Federal do Rio Grande do Sul - UFRGS; e, Universidade Salgado de Oliveira - UNIVERSO. É importante ressaltar, também, que a UFRGS e a UNIASSELVI ainda não possuem, de acordo com o E-MEC, turmas em andamento.

A partir, então, desta delimitação, iniciou-se a procura de informações sobre os referidos cursos em seus sites ${ }^{1}$. As primeiras informações dão conta da distribuição geográfica dos polos de apoio presencial. A figura 2 abaixo mostra esta distribuição:

Figura 2: distribuição geográfica dos polos de apoio presencial.

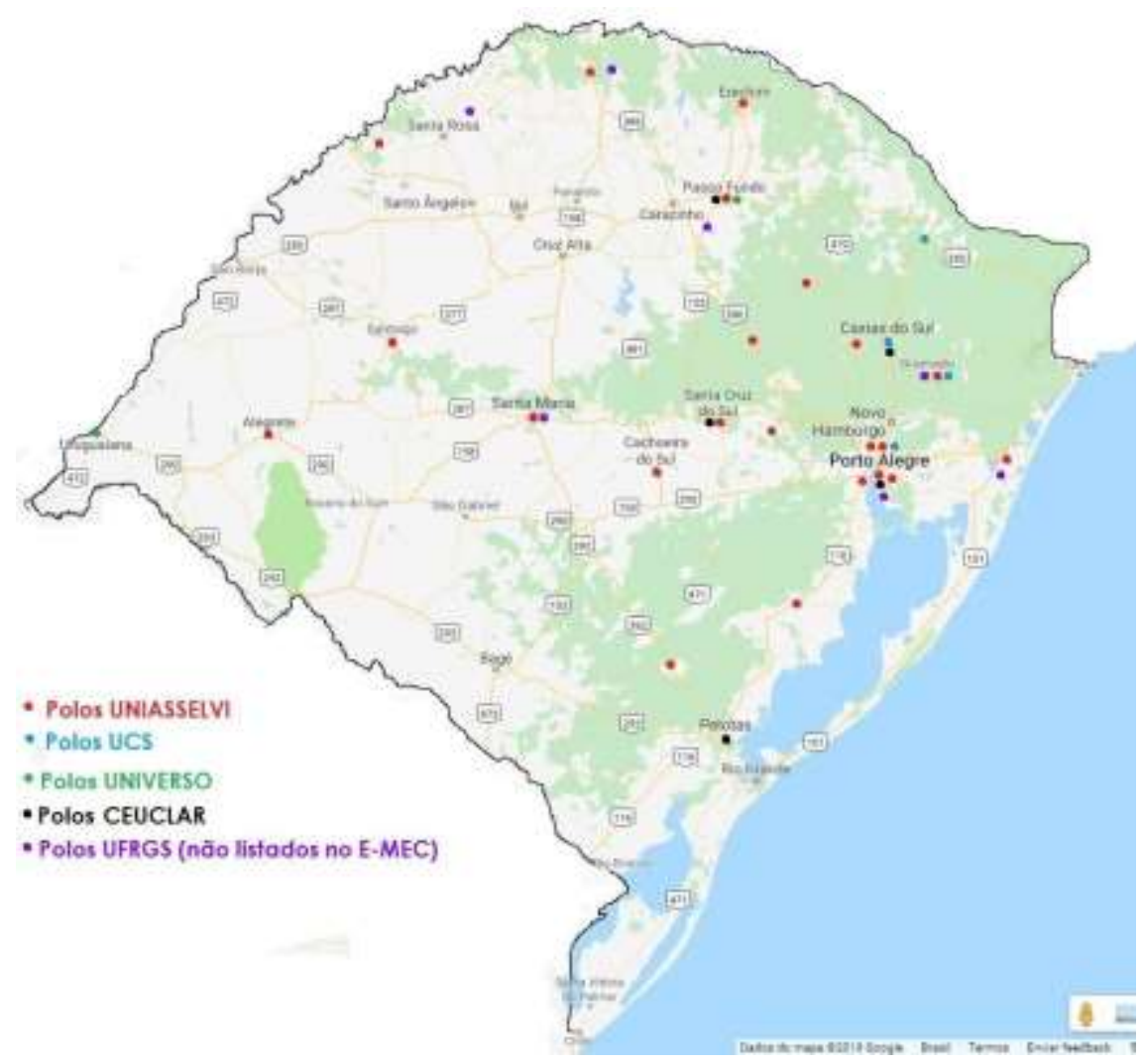

Fonte: elaboração da autora, 2019.

\footnotetext{
${ }^{1}$ A saber: UNIVERSO - https://universo.edu.br/; UNIASSELVI - https://portal.uniasselvi.com.br/; CEUCLAR - https://www.claretiano.edu.br/; UCS - https://www.ucs.br/site; UFRGS https://www.ufrgs.br/bibead//). Todas as informações trazidas aqui são dados públicos, de disponibilidade geral a qualquer pessoa com acesso à internet. Acesso em 05 ago. 2019.
} 
A primeira observação a ser feita refere-se aos polos de apoio presencial da UFRGS. Na consulta ao E-MEC, não foram listados polos de apoio presencial para essa universidade. No entanto, em seu site, há a informação do oferecimento das turmas nas cidades marcadas no mapa acima. Observa-se na figura acima, uma predominância de polos de apoio presencial na região Norte/Leste do estado do Rio Grande do Sul e, em especial, na região metropolitana de Porto Alegre (capital do estado). Este fato decorre do maior potencial econômico desta região.

As universidades a oferecer o curso de Biblioteconomia a distância no Rio Grande do Sul, são todas particulares, com exceção da UFRGS, que é pública. Com relação aos valores de suas mensalidades, temos o gráfico abaixo:

Gráfico 1: valores de mensalidade.

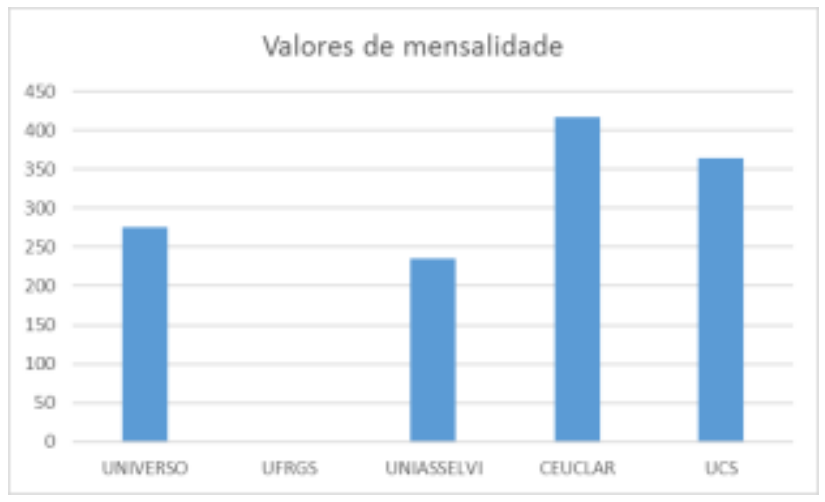

Fonte: elaboração da autora, 2019.

Vê-se a CEUCLAR como a universidade com o maior valor de mensalidade ( $R \$ 416,67)$; e, a UNIVERSO, como a universidade com o menor valor ( $R \$ 275,00)$. O valor médio praticado pelas universidades é de $R \$ 258,30$. Com relação a carga horária total prevista para os cursos de Biblioteconomia a distância no Rio Grande do Sul, tem-se o gráfico abaixo: 
Gráfico 2: carga horária total.

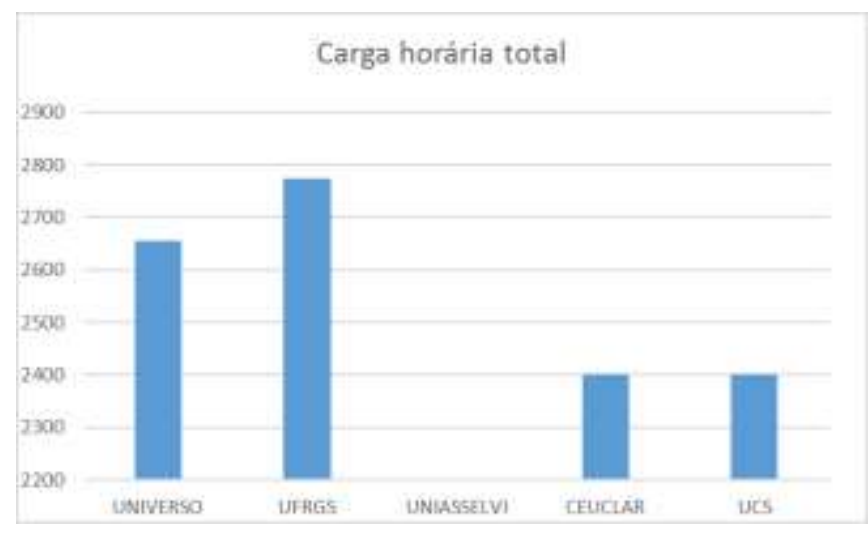

Fonte: elaboração da autora, 2019.

Observa-se que a UFRGS possui o curso de Biblioteconomia a distância com maior carga horária (2.775 horas); CEUCLAR e UCS, como os cursos com menor carga horária prevista (2.400 horas). O valor médio da carga horária para os referidos cursos é de 2.557,5 horas. É importante mencionar que neste gráfico não há dados sobre a carga horária da UNIASSELVI; fato este, que se repetirá em outras situações. Não há no site desta instituição, informações suficientes sobre carga horária e currículo do curso de Biblioteconomia na modalidade a distância.

Verificando a matriz curricular dos referidos cursos, percebe-se um rol de disciplinas específicas da área da Biblioteconomia comuns a todos eles. São elas: fontes de informação, representação temática, formação e desenvolvimento de coleções, representação descritiva, estágio supervisionado, serviço de referência e estudo de usuários. É comum a todos os cursos, carga horária referente a horas complementares de estudos. Assim, no gráfico 3 abaixo, visualizam-se as médias de carga horária dispensadas a cada uma dessas disciplinas pelas universidades pesquisadas: 
Gráfico 3: disciplinas comuns a todos os cursos.

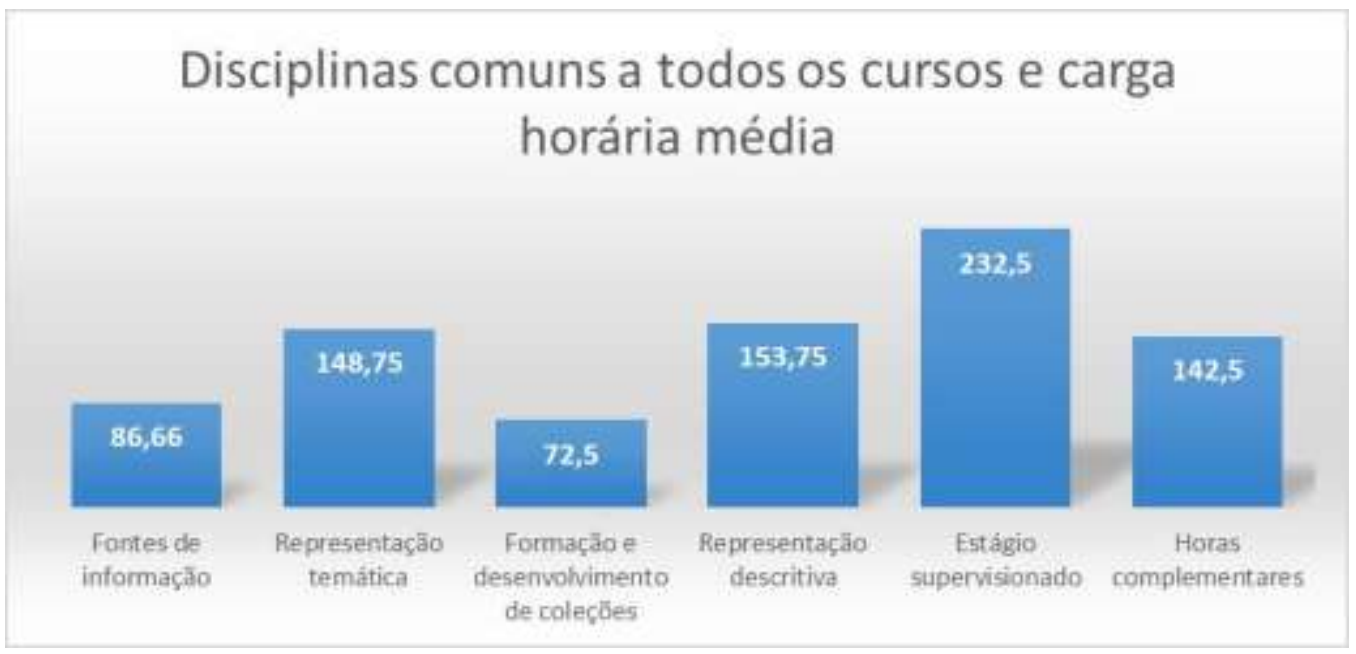

Fonte: elaboração da autora, 2019.

Percebe-se que o estágio supervisionado tem destaque dentro da carga horária média dos cursos pesquisados. Além deste, as disciplinas de representação descritiva e temática também despontam como as com maior carga horária média. Quanto ao estágio, tal fato pode ser atribuído à exigência da legislação quanto ao estágio curricular no final do curso e, também, à necessidade dos alunos em vivenciar a prática profissional. Quanto às disciplinas de representação temática e descritiva, o fato de receberem destaque deve-se ao próprio trabalho desenvolvido pelo Bibliotecário, que em muito ainda está atrelado à classificação e catalogação de materiais.

A legislação educacional que rege os cursos de Biblioteconomia, divide sua carga horária em disciplinas gerais e disciplinas específicas. Para fins deste estudo, ampliou-se esta divisão. Dividiu-se a carga horária dos cursos pesquisados em: disciplinas específicas (não comuns a todos os cursos), disciplinas administrativas, disciplinas relacionadas à informação e às TICs, pesquisa, disciplinas de conhecimentos gerais, disciplinas introdutórias, TCC e disciplinas específicas (comuns a todos os cursos).

Como dito, são disciplinas específicas da área da Biblioteconomia comuns a todos os cursos: fontes de informação, representação temática, formação e desenvolvimento de coleções, representação descritiva, estágio supervisionado, 
serviço de referência e estudo de usuários. É comum a todos os cursos, carga horária referente a horas complementares de estudos.

Outras disciplinas específicas da área da Biblioteconomia, não comuns entre os cursos pesquisados, são: Análise documentária; Normalização de documentos; Técnicas de conservação e preservação de documentos; Editoração eletrônica; Ação cultural; Estudos métricos; Planejamento de unidades de informação; Controle de vocabulário; Indexação e resumos; Publicações digitais; e, Linguagens documentárias.

Dentre as disciplinas administrativas elencam-se: Administração de centros de informação; Marketing em unidades de informação; Dinâmica organizacional; Psicologia organizacional e do trabalho; Fundamentos de teoria organizacional; Empreendedorismo; Organização, sistemas e métodos; Administração; Processos organizacionais; Marketing; Administração de serviços; Teoria geral da administração; Gestão de pessoas; e, Autoconhecimento e liderança.

Já dentre as disciplinas relacionadas à informação e às TICs, listam-se: Introdução às Tecnologias de Informação e Comunicação; Ambientes, Serviços e Sistemas Informacionais; Bases Teóricas da Administração de Ambientes de Informação; Organização, Sistemas e Métodos Aplicados a Ambientes de Informação; Planejamento de Ambientes de Informação; Informatização de Ambientes de Informação; Marketing em Ambientes de Informação; Políticas de Informação; Políticas de Organização e Representação da Informação; Recuperação da Informação; Redes de Computadores; Bibliotecas Digitais; Gestão da Informação e do Conhecimento; Planejamento e Elaboração de Bases de Dados; Serviços de Informação em Rede; Informatização de bibliotecas e recuperação da informação; Gestão de Bibliotecas Digitais e Virtuais; Sistemas de Informação Automação; Informatização em Unidades de Informação; Projeto - Automação e Informatização de Unidades de Informação; e, Arquitetura da Informação e Usabilidade.

Entre as disciplinas de Pesquisa, têm-se: Metodologia da Pesquisa Científica I; Metodologia da Pesquisa Científica II; Métodos Quantitativos, Qualitativos e Mistos de Pesquisa; Metodologia Científica; Métodos Quantitativos; Seminário Interdisciplinar: Introdução à Pesquisa; Estudos Transversais I à V (Online EAD); Seminário Interdisciplinar: Organização de Bibliotecas; e, Tópicos Especiais. 
Já entre as disciplinas de conhecimentos gerais, vê-se: Introdução a Educação a Distância; Introdução a Filosofia; Língua Portuguesa; Sociologia Geral; Inglês Instrumental; Estatística; Noções de Direito; Ética; Política e Sociedade; Economia; Acessibilidade e Inclusão Digital; Língua Brasileira de Sinais; Comunicação e Linguagem; Fundamentos de Educação; Relações Étnico-Raciais e Direitos Humanos; Antropologia; Ética e Cultura; Estudos Literários e Linguísticos aplicados à Biblioteconomia; Evolução dos registos humanos; Sociedade, Cultura e Cidadania; Estudos Literários; Sociologia Aplicada; Filosofia e Lógica; Ética, valores humanos e transdisciplinariedade; Psicologia Social; Teoria da Literatura; e, Introdução à História da Arte.

E, por fim nas disciplinas introdutórias, listam-se: Biblioteconomia e Interdisciplinaridade; Biblioteconomia e Sociedade; Informação, Comunicação e Documento; Organização do Conhecimento e da Informação; Análise da Informação; Bibliotecário: formação e campo de atuação profissional; Perspectivas Profissionais; Fundamentos da Biblioteconomia e Ciências da Informação; Introdução à Biblioteconomia; e, Introdução à Biblioterapia.

Vê-se nos gráficos abaixo, a divisão da carga horária nas diferentes universidades que oferecem o curso de Biblioteconomia a distância no Rio Grande do Sul:

Gráfico 4: CEUCLAR - divisão de carga horária.

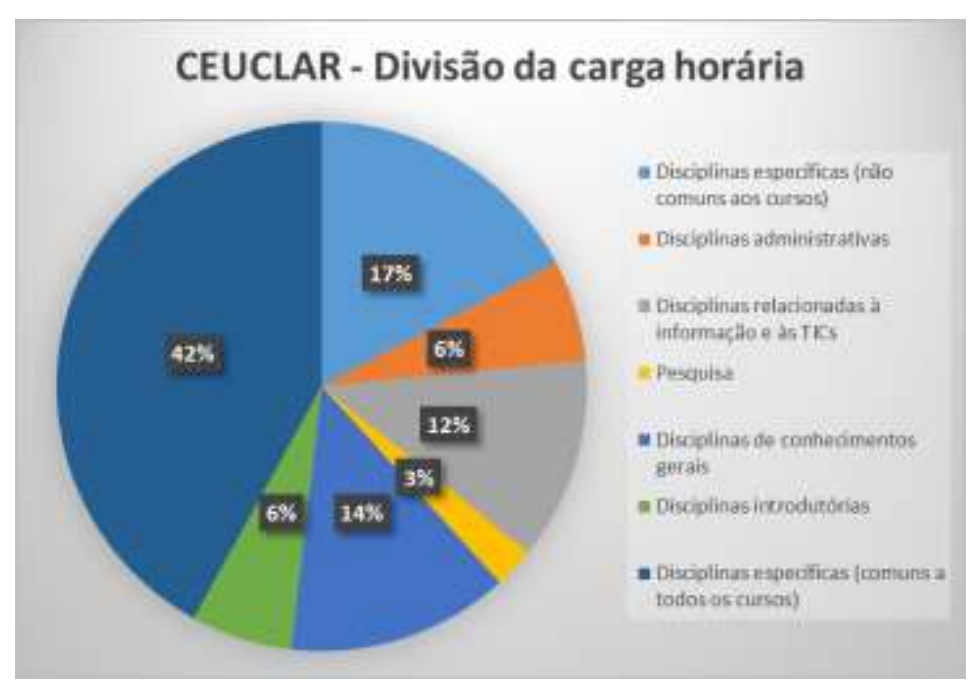

Fonte: elaboração da autora, 2019. 
Gráfico 5: UNIVERSO - divisão de carga horária.

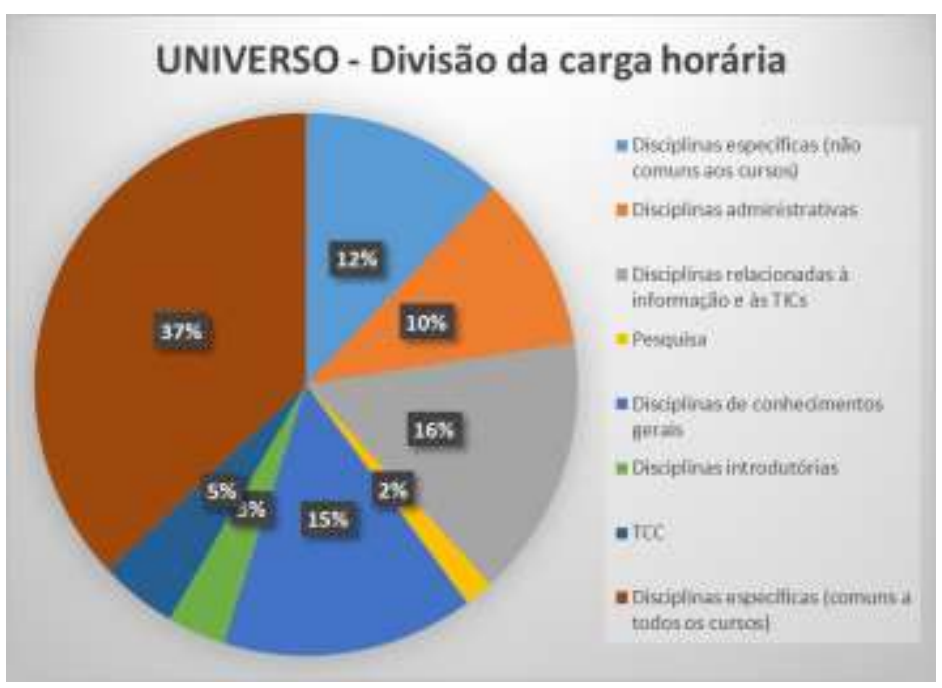

Fonte: elaboração da autora, 2019.

Gráfico 6: UCS - divisão de carga horária.

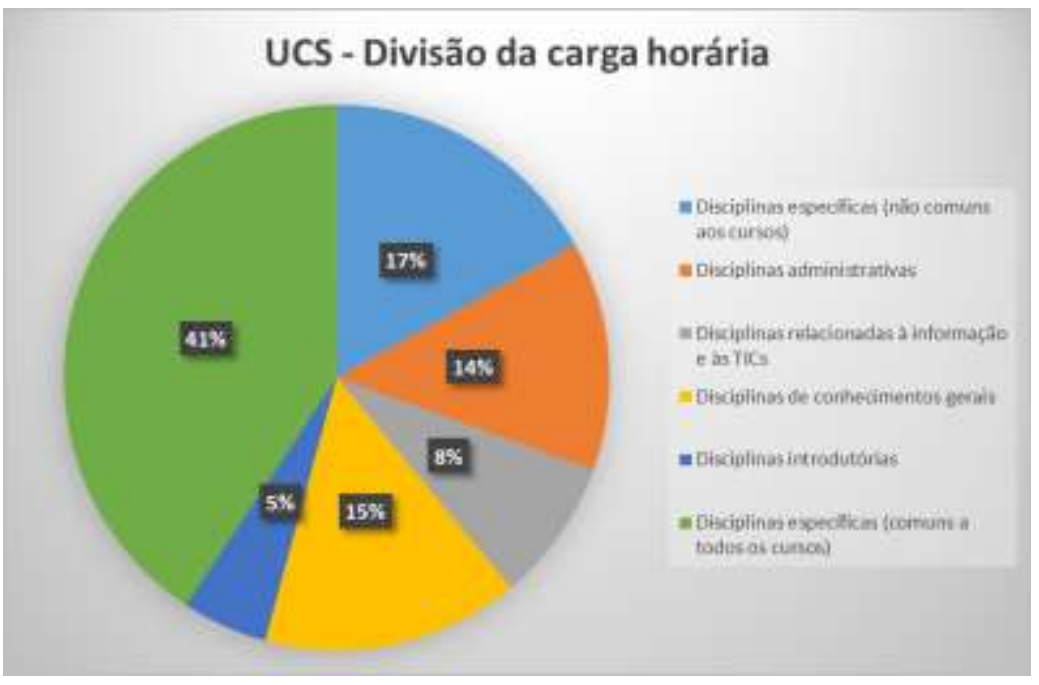

Fonte: elaboração da autora, 2019. 
Gráfico 7: UFRGS - divisão de carga horária.

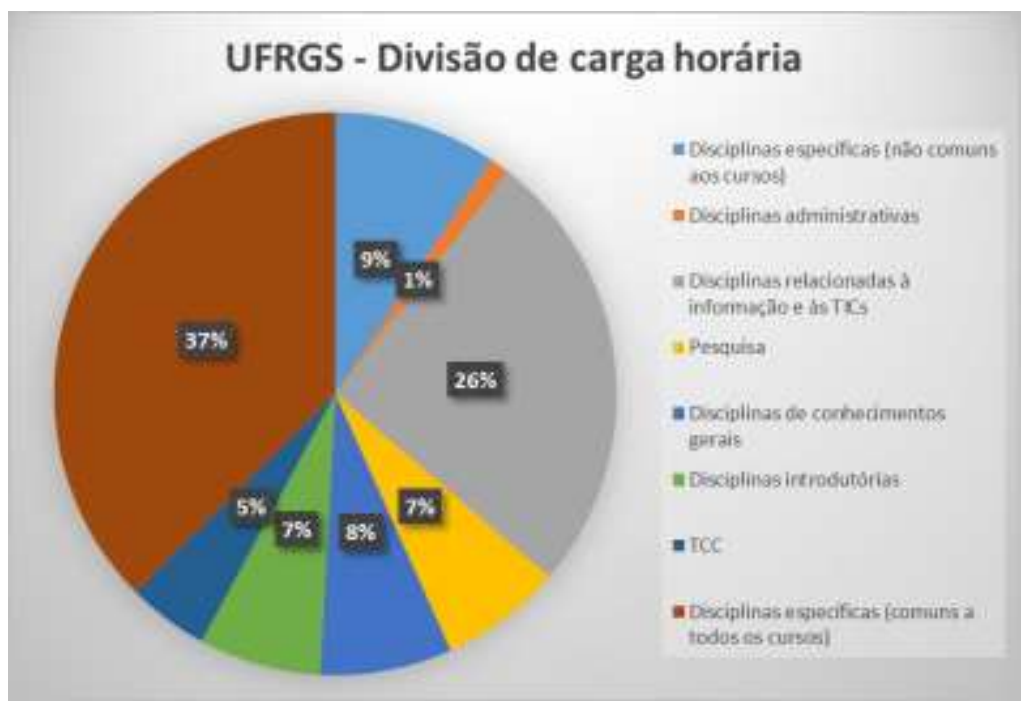

Fonte: elaboração da autora, 2019.

Percebe-se nos gráficos que a CEUCLAR e a UCS focam seus cursos em disciplinas de conhecimentos gerais; já a UNIVERSO e a UFRGS, focam seus currículos em disciplinas relacionadas à informação e às TICs. Vê-se, agora, um gráfico comparativo:

Gráfico 8: comparativo de divisão de carga horária.

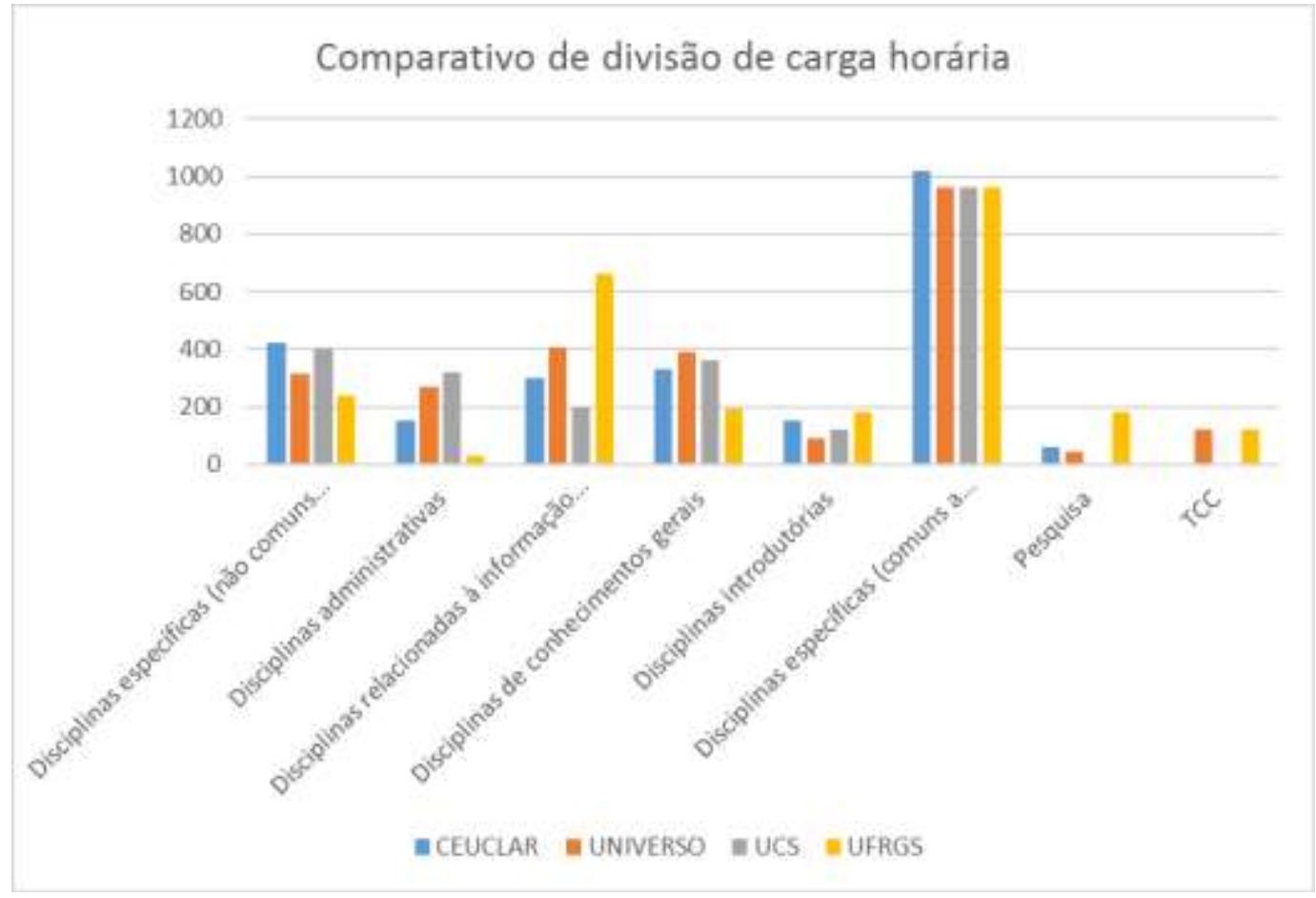

Fonte: elaboração da autora, 2019. 
Assim, a partir dos gráficos apresentados, vê-se que, em média, tem-se $53 \%$ da carga horária dos cursos sendo destinada a disciplinas específicas. A CEUCLAR é a universidade que mais ocupa sua carga horária com disciplinas específicas (59\%). A UFRGS, é a que menos ocupa (46\%).

Após as disciplinas específicas, as disciplinas relacionadas à informação e às TICs ganham destaque. Em média, $15,5 \%$ da carga horária é destinada a elas. $A$ UFRGS é a que possui maior carga horária destinada a estas disciplinas (26\%); a UCS, a que possui menor carga horária (8\%). As disciplinas de conhecimentos gerais as seguem. Em média, $13 \%$ da carga horária é destinada a elas. A UFRGS é a que menos ocupa sua carga horária com estas disciplinas (8\%); a UCS e a UNIVERSO, as que mais ocupam (15\%).

As disciplinas administrativas representam, em média, 7,75\% da carga horária dos cursos pesquisados. A UFRGS é a instituição que menos dedica carga horária a estas disciplinas (1\%); a UCS, a que mais dedica (14\%).

Disciplinas introdutórias à Biblioteconomia ocupam, em média, 6,5\% da carga horária dos cursos pesquisados. A UNIVERSO é a universidade que possui maior carga horária destas disciplinas (8\%); a CEUCLAR, a com menor carga horária (6\%).

Disciplinas relacionadas à Pesquisa representam, em média, 3\% da carga horária dos cursos pesquisados. A UFRGS é a instituição com maior carga horária nesta área (7\%); sendo a UCS a única a não ter carga horária dedicada a esta área.

A carga horária dedicada ao Trabalho de Conclusão de Curso é de, em média, 3,25\%. A UFRGS é a instituição com maior carga horária nesta área; UCS e CEUCLAR não preveem esta disciplina em seus currículos. Sobre os estágios curriculares vale observar que já foram mencionados acima. Em média, 232,5 horas são destinadas a esse fim. Todos os cursos preveem estágio em seus currículos; até porque esta é uma exigência legal. Outras exigências legais, dizem respeito à autorização para o funcionamento do curso e à avaliação dos cursos. A partir dos dados do Sistema E-MEC, temos que: 
Quadro 1: avaliações institucionais e dos cursos de Biblioteconomia Ead.

\begin{tabular}{|c|c|c|c|c|c|c|c|c|}
\hline \multirow[t]{2}{*}{ Universidade } & \multirow{3}{*}{\begin{tabular}{|c|} 
Início do \\
funcionamento
\end{tabular}} & \multirow{3}{*}{$\begin{array}{c}\text { Situação do } \\
\text { funcionamento }\end{array}$} & \multirow{3}{*}{$\begin{array}{c}\text { Vagas anuais } \\
\text { autorizadas }\end{array}$} & \multicolumn{4}{|c|}{ Índices da instituição } & \multirow{2}{*}{$\begin{array}{c}\text { Índices dos } \\
\text { cursos }\end{array}$} \\
\hline & & & & $\mathrm{Cl}$ & $\mathrm{Cl}$ - EAD & IGC - Índice & IGC contínuo & \\
\hline & & & & & & geral dos cursos & & \\
\hline UCS & $04 / 03 / 2013$ & Em atividade & 120 & 4 & 4 & 3 & 29095 & Nenhum \\
\hline UFRGS & Não iniciado & Em atividade & 320 & 4 & 4 & 5 & 43113 & dos cursos \\
\hline UNIASSELVI & Não iniciado & Em atividade & 2000 & 4 & - & 3 & 27025 & possui \\
\hline UNIVERSO & $01 / 02 / 2014$ & Em atividade & 2000 & 3 & - & 3 & 25252 & índices \\
\hline CEUCLAR & $30 / 01 / 2017$ & Em atividade & 1200 & 5 & - & 4 & 30686 & registrados \\
\hline
\end{tabular}

Fonte: elaboração da autora, 2019.

No quadro 1 percebe-se franca vantagem da UFRGS no que e refere à avaliação institucional. Dentre as outras universidades pesquisadas, há certa regularidade. Vê-se que nem todas as universidades passaram por todas as etapas de avaliação. Apenas UCS e UFRGS tem conceitos institucionais relacionados a EAD (CI-EAD) já estabelecidos. A CEUCLAR destaca-se pelo CI mais alto; a UFRGS pelo IGC geral mais alto; a UNIVERSO tem destaque negativo, os menores índices em CI e IGC geral.

Parte-se, agora, para outro ponto de análise: os discursos das universidades que oferecem Biblioteconomia a distância oferecidos no Rio Grande do Sul (RS). Para tal, dividiram-se as informações encontradas em seus sites em categoriais:

VISÃO PRÉVIA: a Biblioteconomia é uma profissão centenária. Atualmente regulamentada pela lei 4.084, muito ainda relacionada somente com os livros em uma biblioteca. As universidades concordam que Biblioteconomia é mais que isso.

QUEM É O BIBLIOTECÁRIO? Os Bibliotecários compõem o elenco dos chamados "profissionais da informação", são credenciados como um dos profissionais mais exigidos do século XXI.

OBJETO DE TRABALHO: todo tipo de informação

TAREFAS DO BIBLIOTECÁRIO: gestão da informação nos diferentes contextos; Planejamento (físico e organizacional), desenvolvimento, implementação, organização, gerência de acervos e processos informacionais/bibliotecários de diferentes unidades de informação e documentação; Avaliação; Assessoria; 
Consultoria; Ensino; Pesquisa; Fiscalização técnica; Promoção, produção e difusão do acesso e do uso do conhecimento; Auxílio aos usuários no acesso e seleção de fontes de informação; Preservação, conservação e tratamento de livros e documentos.

HABILIDADES NECESSÁRIAS: formação abrangente, olhar crítico e qualidade intelectual.

O QUE É OFERECIDO PELAS UNIVERSIDADES: conhecimentos nas áreas de gestão da informação, fundamentos da educação, pesquisa, automação e informatização; Supervisão e orientação de professores e profissionais da área; Ênfase na autonomia dos estudantes; Foco nas estratégias de aprendizagem ativas; Flexibilidade da educação a distância; Matriz curricular atualizada.

MERCADO DE TRABALHO: é visto de forma bastante promissora por todas as universidades que oferecem o curso de Biblioteconomia a distância no Rio Grande do Sul. Fato, este, que se deve a dois fatores: a Lei 12.244, de 24 de maio de 2010, exige uma biblioteca por unidade de ensino no Brasil; há a estimativa de necessidade de 150 mil bibliotecários; Informações digitais: mais bibliotecários para esta área. Especialização em organização da informação em espaços virtuais, um novo campo além Biblioteca física.

LOCAIS DE TRABALHO: Bibliotecas escolares, universitárias, públicas, privadas, pessoais, empresariais e comunitárias; Empresas; Provedores de internet; Arquivos; Centros e/ou Institutos de pesquisa; Bancos; Museus; Centros de documentação e informação; Centros culturais e de memória; Órgãos de gestão do patrimônio cultural; Hemerotecas; Editoras; Livrarias; Empresas de comunicação; ONGs; Clubes e associações; Empresas ou bibliotecas digitais que lidam com organização de conteúdo em espaços virtuais; Galerias de Arte; Serviços como Autônomos; Serviços ou redes de informação; Mídias sociais; Órgãos públicos de inteligência militares e governamentais; Redes de televisão; Hospitais. 


\section{CONSIDERAÇÕES FINAIS}

Cinco são os cursos de Biblioteconomia na modalidade a distância oferecidos no Rio Grande do Sul. As universidades que os oferecem são: CEUCLAR, UNIASSELVI, UCS, UFRGS e UNIVERSO. Estas universidades têm seus polos distribuídos em todo o estado. No entanto, há uma concentração de polos na região Norte/Leste, em especial na região metropolitana de Porto Alegre (capital).

Com exceção da UFRGS, que é pública, as demais instituições são privadas. O valor médio cobrado pela mensalidade é de $\mathrm{R} \$ 258,30$. Os cursos de Biblioteconomia a distância têm duração média de 2.557,5 horas. Deste total de horas, em média $53 \%$ é destinado às disciplinas específicas da área da Biblioteconomia. Após estas, são as disciplinas relacionadas à informação e às TICS que têm mais carga horária (15,5\%); seguidas das disciplinas de conhecimentos gerais (13\%), disciplinas administrativas (7,75\%), disciplinas introdutórias à Biblioteconomia (6,5\%), disciplinas de pesquisa (3\%) e trabalho de conclusão de curso (7\%). Todos os cursos requerem horas de formação complementar e estágio para conclusão do curso.

Retirando da análise as disciplinas específicas da área, observou-se que a CEUCLAR e a UCS focam seus currículos nas disciplinas de conhecimentos gerais; UFRGS e UNIVERSO focam seus currículos em disciplinas relacionadas à informação e às TICs.

Algumas disciplinas são comuns em todos os cursos analisados, a saber: fontes de informação, representação temática, formação e desenvolvimento de coleções, representação descritiva, estágio supervisionado, serviço de referência e estudo de usuários.

Todos os cursos alvo desta pesquisa possuem autorização para funcionamento; no entanto, ainda nem todos foram avaliados pelo MEC. Quanto a avaliação das universidades, temos uma franca vantagem da UFRGS e um destaque negativo para a UNIVERSO.

A Biblioteconomia é vista como uma profissão promissora por todas as universidades; seu objeto de trabalho é a informação. Dentre suas tarefas são listadas pelas instituições: gestão da informação em diferentes contextos; gerência de unidades de informação; planejamento e desenvolvimento dos processos de geração, 
tratamento, armazenamento, conservação, catalogação, disseminação, recuperação e utilização da informação; dentre outros.

Entre seus locais de trabalho as universidades citam: bibliotecas (de todos os tipos); empresas, arquivos, centros de pesquisa, museus, centros de documentação, centros culturais, editoras, livrarias, galerias de arte, serviços ou redes de informação, órgãos públicos, entre outros.

Para bem suceder-se, segundo as instituições pesquisadas, o Bibliotecário necessita de formação abrangente, olhar crítico e qualidade intelectual. Percebe-se que os cursos atendem ao exigido legalmente e também às demandas da formação profissional para o mercado de trabalho do Rio Grande do Sul.

\section{REFERÊNCIAS}

ABREU, Rudimar Serpa de. A educação a distância na universidade comunitária - novas territorialidades: o caso da UNISC no Rio Grande do Sul. Santa Cruz do Sul: UNISC, 2017. 217 f. Tese (Doutorado em Desenvolvimento Regional) - Programa de Pós-graduação em Desenvolvimento Regional, Universidade de Santa Cruz do Sul, Santa Cruz do Sul, 2017. Disponível em:

https://repositorio.unisc.br/jspui/bitstream/11624/1837/1/Rudimar\%20Serpa\%20de\% 20Abreu.pdf. Acesso em: 02 mar. 2019.

ALMEIDA, Neilia Barros Ferreira de; BAPTISTA, Sofia Galvão. Breve histórico da Biblioteconomia brasileira: formação do profissional. In: CONGRESSO BRASILEIRO DE BIBLIOTECONOMIA, DOCUMENTO E CIÊNCIA DA INFORMAÇÃO, 25., 2013, Florianópolis. Anais [...]. Florianópolis: FEBAB, 2013. Disponível em:

https://portal.febab.org.br/anais/article/view/1508. Acesso em: 02 mar. 2019.

ALVES, João Roberto Moreira. A história do Ead no Brasil. In: LITTO, Fredric M.; FORMIGA, Marcos (Org.). Educação a distância: o estado da arte. São Paulo: Prentice Hall, 2009.

\footnotetext{
AMARAL, Lydes Teles Souza do. Expectativa sobre a formação acadêmica e o mercado de trabalho dos ingressantes no curso de Biblioteconomia da UFRN. Natal: UFRN, 2015. 61f. Monografia (Bacharelado em Biblioteconomia) - Curso de Biblioteconomia, Universidade Federal do Rio Grande do Norte, Natal, 2015. Disponível em: http://monografias.ufrn.br:8080/jspui/bitstream/123456789/3812/1/ExpectativaSobreA Formacao Amaral 2015.pdf. Acesso em: 02 mar. 2019.
} 


\section{ASSOCIAÇÃO BRASILEIRA DE EDUCAÇÃO A DISTÂNCIA - ABED. Censo}

EAD.BR: relatório analítico da aprendizagem a distância no Brasil 2017. Curitiba: InterSaberes, 2018.

BRASIL. Lei no 4.084 , de 30 de junho de 1962. Dispõe sobre a profissão de Bibliotecário e regula seu exercício. Brasília: Câmara dos Deputados. Disponível em: http://www.planalto.gov.br/ccivil 03/LEIS/1950-1969/L4084.htm. Acesso em: 02 mar. 2019.

BRASIL. Lei no 9.394, de 20 de dezembro de 1996. Estabelece as diretrizes e bases da educação nacional. Brasília: Câmara dos Deputados. Disponível em: http://www.planalto.gov.br/ccivil 03/LEIS/L9394.htm. Acesso em: 02 mar. 2019.

BRASIL. Ministério da Educação. Cadastro nacional de cursos e instituições de educação superior: cadastro e-mec. [Site institucional]. Disponível em: http://emec.mec.gov.br/. Acesso em: 02 mar. 2019.

CENTRO UNIVERSITÁRIO CLARETIANO - CEUCLAR. [Site institucional]. Disponível em: https://www.claretiano.edu.br. Acesso em: 05 ago. 2019.

CENTRO UNIVERSITÁRIO LEONARDO DA VINCI - UNIASSELVI. [Site institucional]. Disponível em: https://portal.uniasselvi.com.br. Acesso em: 05 ago. 2019.

GOMES, Cândido Alberto da Costa. A legislação que trata da Ead. In: LITTO, Fredric M.; FORMIGA, Marcos (Org.). Educação a distância: o estado da arte. São Paulo: Prentice Hall, 2009.

JOB, Ivone; OLIVEIRA, Dalgiza Andrade. Marcos históricos e legais do desenvolvimento da profissão de Bibliotecário no Brasil. Revista ACB:

Biblioteconomia em Santa Catarina, Florianópolis, v. 11, n. 2, p. 259-272, ago./dez. 2006. Disponível em: https://revista.acbsc.org.br/racb/article/view/449/565. Acesso em 02 abr. 2019.

LITTO, Fredric Michael. O atual cenário internacional da Ead. In: LITTO, Fredric M.; FORMIGA, Marcos (Org.). Educação a distância: o estado da arte. São Paulo: Prentice Hall, 2009.

MACHADO, Maria Elizete Barbosa. Análise curricular dos Cursos de graduação em Biblioteconomia no Brasil: busca pela acessibilidade. Porto Alegre: UFRGS, 2012. 94f. Monografia (Bacharelado em Biblioteconomia) - Faculdade de Biblioteconomia e Comunicação, Universidade Federal do Rio Grande do Sul, Porto Alegre, 2012. Disponível em:

https://www.lume.ufrgs.br/bitstream/handle/10183/69732/000872492.pdf? sequence= 1\&isAllowed=y. Acesso em: 02 mar. 2019. 
NASCIMENTO, Maria Vanessa do; MARTINS, Gracy Kelli. A trajetória das escolas de Biblioteconomia no Brasil. Revista Brasileira de Educação em Ciência da Informação, [Marília], v. 4, n. esp., p. 37-54, 2. sem. 2017. Disponível em: http://abecin.org.br/portalderevistas/index.php/rebecin. Acesso em: 02 mar. 2019.

NUNES, Ivônio Barros. A história da Ead no mundo. In: LITTO, Fredric M.; FORMIGA, Marcos (Org.). Educação a distância: o estado da arte. São Paulo: Prentice Hall, 2009.

PAIVA, Alline Heloise Valle et al. Biblioteconomia: aspectos da formação bibliotecária no contexto brasileiro. Revista Informação na Sociedade Contemporânea, Natal, v. 1, n. 2, jan./jun. 2017. Disponível em: https://periodicos.ufrn.br/informacao/article/view/11578/8154. Acesso em: 02 mar. 2019.

RUSSO, Mariza. Inovação no ensino da Biblioteconomia no Brasil: implantação do Bacharelado na modalidade de Educação a Distância. Informação e Sociedade: Estudos, João Pessoa, v. 26, n. 1, p. 21-35, jan./abr. 2016. Disponível em: http://www.periodicos.ufpb.br/ojs/index.php/ies/article/view/28772/15526. Acesso em: 02 mar. 2019.

RUSSO, Mariza; FONSECA, Marcus Vinícius de A.; BARBALHO, Célia Regina Simonetti. Formação em Biblioteconomia a distância: a implantação do modelo no Brasil e as perspectivas para o mercado de trabalho do bibliotecário. Informação e Sociedade: Estudos, João Pessoa, v. 22, n. 3, p. 61-81, set./dez. 2012. Disponível em: http://www.periodicos.ufpb.br/ojs/index.php/ies/article/view/14387/8601. Acesso em: 02 mar. 2019.

SAMPIERI, Roberto H.; COLLADO, Carlos F.; LUCIO, María del B. Pilar. Metodologia de pesquisa. 5. ed. Porto Alegre: Penso, 2013.

UNIVERSIDADE ABERTA DO BRASIL. [Site institucional]. Disponível em: http://www.capes.gov.br/uab?view=default . Acesso em: 02 mar. 2019.

UNIVERSIDADE DE CAXIAS DO SUL - UCS. [Site institucional]. Disponível em: https://www.ucs.br/site. Acesso em: 05 ago. 2019.

UNIVERSIDADE FEDERAL DO RIO GRANDE DO SUL - UFRGS. [Site institucional]. Disponível em: https://www.ufrgs.br/bibead. Acesso em: 05 ago. 2019.

UNIVERSIDADE SALGADO DE OLIVEIRA - UNIVERSO. [Site institucional]. Disponível em: https://universo.edu.br. Acesso em: 05 ago. 2019. 